\title{
KARAKTERISTIK MORTAR MENGGUNAKAN BIOPOZZOLAN SEBAGAI PENGGANTI SEBAGIAN SEMEN
}

\author{
Nunung Martina ${ }^{1}$, Seira Diwama Cathelina ${ }^{2}$, Zahara Tunnur ${ }^{2}$ \\ 1,2,3 Jurusan Teknik Sipil Politeknik Negeri Jakarta Jl. Prof.Dr.G.A.Siwabessy, Kampus UI Depok 16425 \\ nunung.martina@sipil.pnj.ac.id, seiradiwamac@gmail.com \\ ztunnur@gmail.com
}

\begin{abstract}
This research uses Bio-pozzolan which consist of ASP and lime as a substitute for cement which is expected to be used in the manufacture of mortar. Mortar mixtures were tested with a total of 70 specimens, including compressive strength of 45 specimens according to SNI 03 - 6825 - 2002, flexural strength of 15 specimens according to ASTM C $580-02$, and changes in length of 10 specimens according to ASTM C 157 - 93. Mortar specimens with a comparison ratio of 1 PC : 3 Aggregate, the adhesive material is partially replaced with a Bio-pozzolan adhesive consisting of ASP and lime. The amount of cement substitution with Bio-pozzolan is $17,5 \%$ of the weight of cement. In this research the variation of bio-pozzolan as follows; variation 1 (0\% Bio-pozzolan), variation 2 (50\% lime: 50\% RHA), variation 3 (60\% lime: $40 \%$ RHA), variation 4 (70\% lime: 30\% RHA), variation 5 (80\% lime: $20 \%$ RHA). The results showed the composition of Bio-pozzolan variation 2 produces compressive strength with a value of 20,889 MPA, flexural strength is 6,3735 MPA, and a value of change in length with the lowest shrinkage expansion. This Bio-pozzolan Mortar variation 2 is included into the mortar type M.
\end{abstract}

Keywords : Rice Husk Ash, Quicklime, Mortar, compressive strength, flexural strength, length change.

\begin{abstract}
ABSTRAK
Penelitian ini menggunakan Biopozzolan yang terdiri dari abu sekam padi (ASP) dan kapur sebagai pengganti sebagian semen yang diharapkan dapat dimanfaatkan dalam pembuatan mortar. Campuran mortar yang diuji dengan total benda uji sebanyak 70 buah, meliputi kuat tekan 45 benda uji sesuai standar SNI 03 - 6825 - 2002, kuat lentur 15 benda uji sesuai standar ASTM C 580-02, dan perubahan panjang sebanyak 10 benda uji sesuai standar ASTM C 157 - 93. Benda uji berupa mortar dengan perbandingan komposisi 1 Pc ; 3 Psr, bahan perekat isi diganti sebagian dengan perekat Biopozzolan yang terdiri dari ASP dan kapur. Jumlah substitusi semen dengan biopozzolan sebesar 17,5\% dari berat semen. Pada pebelitian ini Biopozzolan divariasikan sebagai berikut; variasi 1 (0\% Biopozzolan), variasi 2 (50\% Kapur : 50\% ASP), variasi 3 (60\% Kapur : 40\% ASP), variasi 4 (70\% Kapur : $30 \%$ ASP), variasi 5 (80\% Kapur : 20\% ASP). Hasil penelitian didapatkan komposisi Biopozzolan variasi 2 menghasilkan kuat tekan dengan nilai 20,899 Mpa dan kuat lentur dengan nilai 6,3735 MPa serta nilai perubahan panjang dengan muai susut paling rendah. Mortar Biopozzolan variasi 2 ini termasuk tipe M.
\end{abstract}

Kata kunci : Abu Sekam Padi, Kapur, Mortar, kuat tekan, kuat lentur, perubahan panjang.

\section{PENDAHULUAN}

\section{Latar Belakang}

Seiring dengan pesatnya perkembangan infrastruktur maka semakin besar kebutuhan bahan bangunan. Sebagian besar bahan bangunan berasal dari alam, sedangkan bahan alam tidak dapat diperbarui. Untuk menanggulangi masalah tersebut perlu dilakukan inovasi penggantian banhan bangunan dengan bahan lain yang memiliki karakteristik mendekati sama. Salah satu bahan bangunan yang dapat digantikan dengan bahan lain adalah semen. Semen terdiri dari bahan-bahan yang terutama mengandung kapur, silika dan oksida besi. Penggunaan bahan pengganti sebagian semen melalui komposisi 
campuran yang inovatif akan mengurangi jumlah semen. Abu sekam padi merupakan sumber pozzolan potensil sebagai SCM (Supplementary Cementitious Material). Abu sekam padi memiliki aktivitas pozzolanic yang sangat tinggi sehingga lebih unggul dari SCM lainnya seperti fly ash, slag, dan silica fume. Beberapa hasil ikutan industri dan pertanian seperti slag, fly ash, abu sekam padi ternyata merupakan polutan potensil yang dapat digunakan sebagai bahan subtitusi atau bahan tambahan semen (Bakri, 2009). Dalam penelitian ini akan dicoba dengan pembakaran abu sekam padi yang memiliki kandungan sebagian besarnya silika. Penggunaan Abu sekam padi secara signifikan meningkatkan kekuatan mortar dan dapat digunakan sebagai bahan pozzolan dalam mortar semen. Namun, penggilingan halus dan pembakaran dalam suhu terkontrol mungkin diperlukan untuk mendapatkan abu sekam padi berkualitas baik. (Munshi, dkk, 2013). Sekam padi merupakan salah satu limbah pertanian yang belum banyak dimanfaatkan menjadi produk yang mempunyai nilai tambah. Sekam padi memiliki komponen kimia $\mathrm{SiO} 2, \mathrm{Fe} 2 \mathrm{O} 3$, dan Al2O3 yang dapat ditambahkan sebagai bahan additive pada semen. Kandungan komponen kimia dari abu sekam padi yaitu $\mathrm{SiO} 2$ sebesar 93,65\%, $\mathrm{Fe} 2 \mathrm{O} 3$ sebesar 2,74\%dan $\mathrm{Al} 2 \mathrm{O} 3$ sebesar 0,78\% (Ningsih, dkk, 2012).

Untuk mengoptimalkan fungsi abu sekam padi maka ditambahkan kapur karena dalam abu sekam padi tidak memiliki kandungan kapur. Pemanfaatan biopozzolan abu sekam padi sebagai fly ash dalam pembuatan semen untuk meningkatkan kualitas fisis mortar. Penelitian ini menunjukkan bahwa mortar yang dicampur abu sekam padi dapat meningkatkan kuat tekan mortar. Adapun peningkatan kekuatan tekan dengan perbandingan campuran yang optimum adalah $17,5 \%$ biopozzolan dari berat semen (Maya,dkk, 2012). Abu sekam padi tidak dapat digolongkan sebagai matriks semen karena tidak mengandung C3S dan C2S tetapi dapat digunakan sebagai pengganti sebagian semen untuk menghasilkan CSH sekunder dalam pembuatan komposit semen (Bakri, 2009). Dengan latar belakang diatas maka dilakukan penelitian untuk mendapatkan karakteristik mortar dengan menggunakan biopozzolan yang terdiri dari abu sekam padi dan kapur sebagai pengganti sebagian semen. Penelitian ini diharapkan dapat menghasilkan bahan alternatif pengganti semen.

\section{Tujuan Penelitian}

Tujuan yang akan dicapai setelah penelitian ini :

1. Untuk mendapatkan karakteristik mortar biopozzolan yang ditinjau dari sifat fisik dan mekanis mortar.

2. Untuk mendapatkan komposisi optimum biopozzolan yang dapat digunakan sebagai substitusi semen ditinjau dari kuat tekan.

\section{Manfaat Penelitian}

Adapun manfaat dari penelitian ini, antara lain :

1. Dapat mengurangi penggunaan semen dan dan meningkatkan penggunaan limbah abu sekam padi

2. Dapat mengetahui apakah biopozzolan dapat digunakan sebagai substitusi semen

3. Bagi masyarakat kampus, hasil penelitian ini dapat digunakan sebagai bahan pengayaan dalam pengajaran dan untuk melakukan penelitian lebih lanjut tentang abu sekam padi dan kapur sebagai substitusi dalam pembuatan mortar. 


\section{METODE PENELITIAN}

Pada penelitian ini, digunakan metode eksperimen dengan pengujian langsung di laboratorium sesuai dengan data-data yang dibutuhkan dan mengacu pada peraturan SNI maupun standar ASTM. Metode eksperimen dengan menggunakan beberapa variasi abu sekam padi dan kapur sebagai substitusi semen diharapkan menghasilkan sifat kuat tekan, kuat lentur, dan perubahan panjang yang baik dari mortar semen dengan komposisi perbandingan berat 1 PC : 3 Pasir, semen diganti sebagian dengan perekat biopozzolan yang terdiri dari ASP dan kapur. Jumlah substitusi semen dengan biopozzolan sebesar $17,5 \%$ dari berat semen. Pada penelitian ini biopozzolan divariasikan sebagai berikut; variasi 1 (0\% biopozzolan), variasi 2 (50\% Kapur : 50\% ASP), variasi 3 (60\% Kapur : $40 \%$ ASP), variasi 4 (70\% Kapur : $30 \%$ ASP), variasi 5 (80\% Kapur : 20\% ASP). Diagram Alir Penelitian dapat dilihat pada Gambar 1.

\section{HASIL dan PEMBAHASAN}

\section{Hasil Pengujian Konsistensi}

Hasil Pengujian Konsistensi Mortar biopozzolan dapat dilihat di Tabel 1.

\section{Hasil Pengujian Kuat Tekan}

Kekuatan Tekan adalah sifat kemampuan menahan atau memikul suatu beban tekan.

Dari tabel hasil analisa kuat tekan mortar didapatkan hubungan antara variasi biopozzolan dengan uji kuat tekan mortar. Kekuatan tekan yang baik apabila nilai kuat tekan selama 7 hari, 14 hari, dan 28 hari semakin meningkat. Tabel 2 memperlihatkan bahwa sampel dari variasi 1 sampai 5, nilai kuat tekan yang semakin hari semakin naik. Dari data pengamatan diketahui bahwa kekuatan tekan yang paling baik yaitu pada variasi 1 biopozzolan dimana nilai kuat tekannya paling besar. Mortar dengan penambahan biopozzolan mempunyai nilai kuat tekan yang lebih rendah daripada yang tidak ditambahkan. Penurunan pada variasi yaitu variasi 1 sebesar $7,89 \%$, variasi 2 sebesar 12,97\%, 3 sebesar 18,93\%, 4 sebesar $17,95 \%$. Penurunan kuat tekan pada masing - masing variasi mengacu terhadap kuat tekan mortar normal.

\section{Kuat Lentur}

Pada pengujian kuat lentur ini adalah dengan meletakkan benda uji diatas 1 tumpuan yang sejajar kemudian membebaninya dengan beban merata yang terletak ditengah bentang, serta dilakukan penambahan beban secara bertahap hingga mencapai benda uji patah untuk mendapat nilai beban maksimum (Pmaks), dapat dilihat pada Gambar 2.

Hasil pengujian kuat lentur dapat dilihat Tabel 3. Pengujian kuat lentur dilakukan pada umur mortar 28 hari. Dari hasil uji kuat lentur uji mortar biopozzolan dilihat pada tabel 3 bahwa nilai kuat lentur yang didapat dari variasi biopozzolan kemampuan menerima beban turun. Mulai dari variasi 1 sampai dengan variasi 5 nilai kuat lentur terus mengalami penurunan. Kuat lentur tertinggi didapat dari variasi 2 sebesar 6,735 $\mathrm{MPa}$ namun nilai tersebut masih lebih kecil dibandingkan dengan kuat lentur mortar variasi normal yaitu sebesar 6,784 MPa.

\section{Perubahan Panjang}

Perubahan panjang adalah untuk mengetahui muai susut yang dialami oleh mortar dengan perubahan panjang maksimal pada mortar adalah $0,0496 \%$. Hasil Pengujian Kuat Lentur Mortar biopozzolan dapat dilihat di Tabel 3. 
Dari hasil uji Perubahan panjang uji mortar biopozzolan dapat dilihat pada tabel 4 bahwa nilai perubahan panjang yang didapat mengalami Mortar dengan variasi abupenurunan muai susut sekam padi dan kapur mengalami perubahan panjang paling kecil sebesar 0,0007\% hal ini masih sesuai dengan ASTM C 157-99 yaitu perubahan panjang maksimal pada mortar adalah 0,0496\%.

\section{KESIMPULAN}

Berdasarkan hasil dan analisis terhadap pengujian yang telah dilakukan didapatkan beberapa kesimpulan yang tertera sebagai berikut

1. Sifat fisik mortar menggunakan biopozzolan abu sekam padi dan kapur meliputi:

a) Konsistensi mortar biopozzolan tidak sama dengan konsistensi normal mortar semen karena tidak berada diantara konsistensi normal yang disyaratkan menurut SNI 036882-2002 yaitu (105-115) \%. Maka dari itu perlu ditambahkan air agar mencapai konsistensi yang disyaratkan. Kebutuhan air untuk mortar biopozzolan lebih tinggi karena luas permukaan biopozzolan yang tinggi.

b) Perubahan panjang mortar dengan variasi normal maupun biopozzolan mengalami perubahan muai susut yang bervariasi setiap umur pengujiannya.

2. Sifat mekanik motar menggunakan abu sekam padi dan kapur meliputi :

a) Kuat tekan mortar biopozzolan pada umur 28 hari untuk masingmasing variasi menurun dibandingkan dengan kuat tekan mortar normal. Penurunan pada variasi yaitu variasi 2 sebesar 7,89\%, variasi 3 sebesar 12,97\%, variasi 4 sebesar $18,93 \%$, variasi 5 sebesar 17,95\%. Tipe mortar dilihat dari nilai kuat tekan mortar yaitu semua variasi mortar mempunyai kekuatan mortar tipe M dimana nilai kuat tekan lebih dari 17,2 Mpa.

b) Kuat lentur mortar biopozzolan pada umur 28 hari untuk masingmasing variasi menurun dibandingkan dengan kuat lentur mortar normal. Nilai kuat lentur pada setiap variasi yaitu variasi 1 sebesar 6,784 $\mathrm{MPa}$, variasi 2 sebesar 6,735 $\mathrm{MPa}$, variasi 3 sebesar 6,124 $\mathrm{MPa}$, variasi 4 sebesar $5,555 \mathrm{MPa}$ dan variasi 5 sebesar 5,341 MPa.

Pada penelitian ini untuk variasi dengan menggunakan biopozzolan pada mortar, nilai optimum dicapai pada variasi 2 mortar biopozzolan karena memiliki kuat tekan dan kuat lentur lebih tinggi dari variasi biopozzolan lain, namun hasil variasi 2 biopozzolan masih lebih kecil dibandingkan dengan kuat tekan dan kuat lentur mortar variasi normal. Perubahan panjang pada variasi mortar biopozzolan mengalami muai susut yang bervariasi hal ini disebabkan oleh sifat kapur. Kuat tekan pada variasi 2 mempunyai kekuatan mortar tipe $\mathrm{M}$ dimana nilai kuat tekannya lebih dari 17,2 Mpa.

\section{UCAPAN TERIMA KASIH}

Ucapan terima kasih kami sampaikan kepada Jurusan Teknik Sipil Politeknik Negeri Jakarta yang selalu memberikan dukungan sehingga artikel ini dapat terselesaikan.

\section{DAFTAR PUSTAKA}

[1] Bakri, 2009, Komponen Kimia Abu Sekam Padi sebagai SCM untuk Pembuatan Komposit Semen, Jurnal Perrenial, 5-14, 2009. Makassar. 
[2] Maya, Lydia Wanty. 2013. "Pemanfaatan Bipozzolan Abu Sekam Padi Pengganti Fly Ash Dalam Pembuatan Semen Untuk Meningkatkan Kualitas Fisis Mortar”. Universitas Hasanuddin,

[3] Surajit Munshi, Gopinandan Dey and Richi P rasad S., 2013. Use of Rice Straw Ash as Pozzolanic Material in Cement Mortar IACSIT International Journal of Engineering and Technology, Vol. 5, No. 5, October 2013
[4] Ningsih, T., Chairunnisa R., and Miskah, S. 2012. "Pemanfaatan Bahan Additive Abu Sekam Padi Pada Semen Portland PT Semen Baturaja (PERSERO)". Jurnal Teknik Kimia no.4 Vol. 18, 2012

[5] SNI 03-6882-2002, Spesifikasi Mortar Untuk Pekerjaan Pasangan, Badan Standarisasi Nasional, Jakarta: 2002.

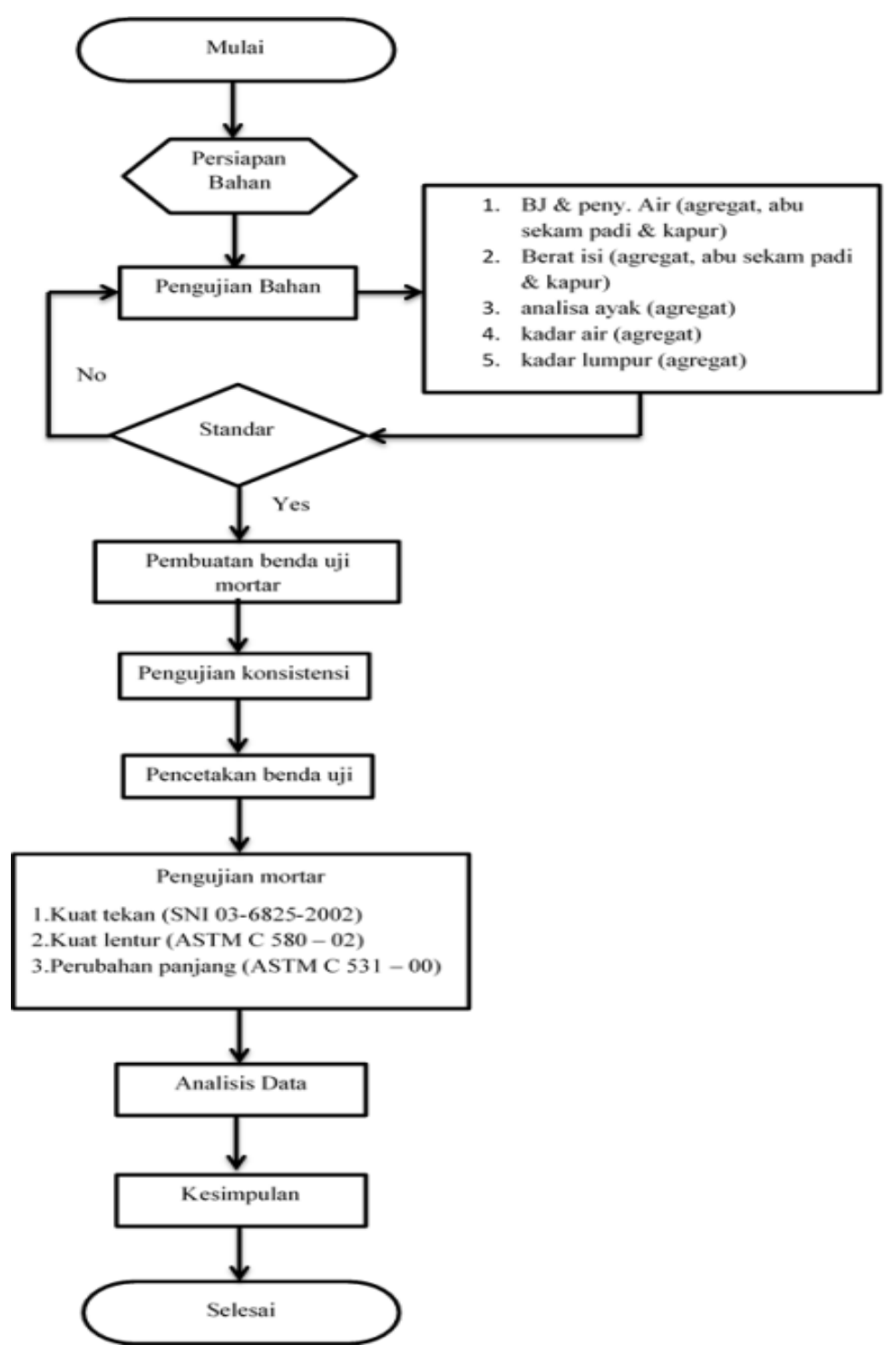

Gambar 1. Diagram Alir Penelitian 


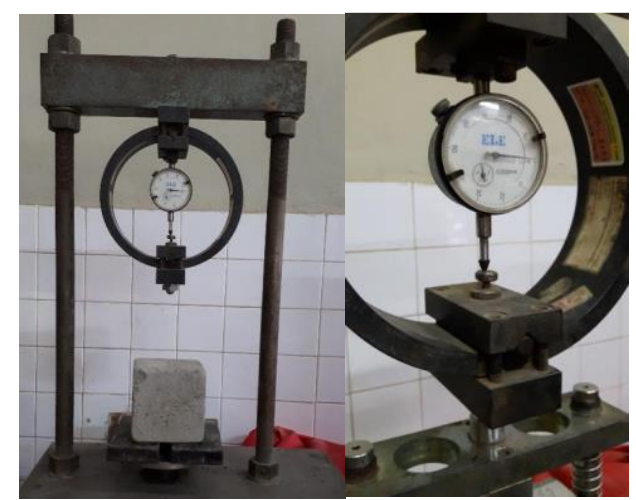

Gambar 2. Pengujian Kuat Lentur

Tabel 1. Hasil Pengujian Konsistensi Mortar Biopozzolan

\begin{tabular}{ccc}
\hline Variasi & Kebutuhan Air $(\mathbf{K g})$ & Nilai Flow \\
\hline Variasi 1 & 0,401 & $110,5 \%$ \\
Variasi 2 & 0,442 & $110,5 \%$ \\
Variasi 3 & 0,442 & $110,5 \%$ \\
Variasi 4 & 0,442 & $110,5 \%$ \\
Variasi 5 & 0,442 & $110,5 \%$ \\
\hline
\end{tabular}

Tabel 2. Hasil Pengujian Kuat Tekan Biopozzolan

\begin{tabular}{cccccc}
\hline \multirow{2}{*}{ Lama Pengujian } & \multicolumn{5}{c}{ Kuat Tekan (MPa) } \\
\cline { 2 - 6 } & Var 1 & Var 2 & Var 3 & Var 4 & Var 5 \\
\hline 7 hari & 17.32 & 13.80 & 12.34 & 13.06 & 13.00 \\
14 hari & 19.93 & 18.70 & 17.91 & 16.41 & 15.96 \\
28 hari & 22.67 & 20.88 & 19.72 & 18.37 & 18.60 \\
\hline
\end{tabular}

Tabel 3. Hasil Pengujian Kuat Lentur Mortar Biopozzolan

\begin{tabular}{cccccc}
\hline \multirow{2}{*}{ Umur } & \multicolumn{5}{c}{ Kuat Lentur (Mpa) } \\
\cline { 2 - 6 } & Var 1 & Var 2 & Var 3 & Var 4 & Var 5 \\
\hline 28 hari & 6.74 & 6.78 & 6.12 & 5.56 & 5.34 \\
\hline
\end{tabular}

Tabel 4. Hasil Pengujian Perubahan Panjang Mortar Biopozzolan

\begin{tabular}{cccccc}
\hline \multirow{2}{*}{ Lama Pengujian } & \multicolumn{5}{c}{ Perubahan Panjang (\%) } \\
\cline { 2 - 6 } & Var 1 & Var 2 & Var 3 & Var 4 & Var 5 \\
\hline 3 hari & 0.0049 & 0.0381 & 0.0242 & 0.0023 & 0.0172 \\
7 hari & 0.0123 & 0.0423 & 0.0330 & 0.0112 & 0.0225 \\
14 hari & 0.0018 & -0.0054 & 0.0032 & 0.0005 & -0.0053 \\
21 hari & -0.0021 & -0.0170 & -0.0011 & -0.0040 & -0.0098 \\
28 hari & -0.0126 & -0.0402 & -0.0007 & -0.0118 & -0.0196 \\
\hline
\end{tabular}

